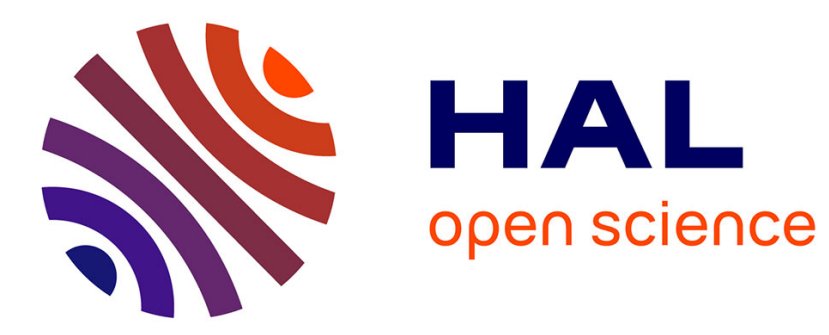

\title{
Molecular dynamics simulation of silver nanoparticles in a europium doped sodosilicate glass
}

Andre Monteil, S. Ghemid, Stéphane Chaussedent, Mohamed El Jouad, M.A. Couto dos Santos

\section{- To cite this version:}

Andre Monteil, S. Ghemid, Stéphane Chaussedent, Mohamed El Jouad, M.A. Couto dos Santos. Molecular dynamics simulation of silver nanoparticles in a europium doped sodosilicate glass. Chemical Physics Letters, 2010, 493 (1-3), pp.118 - 120. 10.1016/j.cplett.2010.05.018 . hal-03187679

\section{HAL Id: hal-03187679 \\ https://univ-angers.hal.science/hal-03187679}

Submitted on 1 Apr 2021

HAL is a multi-disciplinary open access archive for the deposit and dissemination of scientific research documents, whether they are published or not. The documents may come from teaching and research institutions in France or abroad, or from public or private research centers.
L'archive ouverte pluridisciplinaire HAL, est destinée au dépôt et à la diffusion de documents scientifiques de niveau recherche, publiés ou non, émanant des établissements d'enseignement et de recherche français ou étrangers, des laboratoires publics ou privés. 


\title{
Molecular dynamics simulation of silver nanoparticles in a europium doped sodosilicate glass
}

\author{
A. Monteil ${ }^{\text {a,* }}$, S. Ghemid ${ }^{\text {b }}$, S. Chaussedent ${ }^{a}$, M. El Jouad ${ }^{a}$, M.A. Couto dos Santos ${ }^{\text {c }}$ \\ a LPhiA EA 4464, Université d'Angers, 2 bd Lavoisier, 49045 Angers Cedex 01, France \\ ' Physics Department, University of Annaba, Algeria \\ ${ }^{\mathrm{c}}$ Department of Physics, Federal University of Sergipe, Brazil
}

\section{A R T I C L E I N F O}

\section{Article history:}

Received 23 March 2010

In final form 7 May 2010

Available online 12 May 2010

\begin{abstract}
A B S T R A C T
Molecular dynamics simulation is applied to an europium doped sodosilicate glass containing silver $\left[(\mathrm{Na}-\mathrm{Ag})_{2} \mathrm{O}-\mathrm{SiO}_{2}-\mathrm{Eu}_{2} \mathrm{O}_{3}\right]$. The silver is implanted in substitution of $\mathrm{Na}$, simulating an ionic exchange. For ionic interactions a modified Born-Mayer-Huggins potential was employed. For the Ag-Ag interaction, a Lennard-Jones ( $\mathrm{LJ}$ ) potential is applied, while for the Eu-Ag interaction, a modified LJ potential is introduced. The particle size increases with the annealing treatment and follows a lognormal law. After $75 \mathrm{ps}$ the average particle size reaches 5.8 atoms ( 4.8 for $\mathrm{Ag}$ and $1.0 \mathrm{for} \mathrm{Eu}$ ), and it is found that the europium is preferentially situated on these nanoclusters.
\end{abstract}

(c) 2010 Elsevier B.V. All rights reserved.

\section{Introduction}

The application of metallic nanoparticles as a modifier of optical properties of liquid and solid state media is very a nowadays subject on the side of nanophotonics [1-3]. It is important to mention that, in the solid state case, the absence of long range order turns the glasses out to be natural candidates to host metallic nanoparticles [4-9]. In the case of lanthanide ions $\left(\operatorname{Ln}^{3+}\right)$ doped glasses containing silver nanoparticles, the spectroscopic behaviour still lack interpretations, e.g., what really is the effect of the plasmon band on the $\mathrm{Ln}^{3+}$ luminescence or from what size the plasmonic oscillations do interact with transitions between levels [10-16]. Further, the importance of such a kind of study can be verified through very recent applications of silver nanoparticles, which include the antibacterial activity, clinical diagnostics and dental restoration [17-22].

Molecular dynamics (MD) has been largely employed to simulate structure and properties of glasses, rare-earth doped glasses (see e.g., [23]) as well as the nanoparticles growing process in glasses [24-28]. MD has become an important tool, because just by typing and keeping the potentials of interaction within physically acceptable ranges, predictions can be made and one try to envisage non evident experimental or theoretical local features.

In this work a MD study of a europium doped sodosilicate glass containing silver nanoparticles is developed, with the aim of obtaining Ag-Eu nanoalloy. To this end, for all ionic interaction, a modified Buckingham potential is employed and, for the $\mathrm{Eu}-\mathrm{Ag}$

\footnotetext{
* Corresponding author. Fax: +3324173 5216 .

E-mail address: andre.monteil@univ-angers.fr (A. Monteil).
}

metallic interaction, it is introduced a modified Lennard-Jones (LJ) potential.

\section{MD procedures}

For all ionic interaction a modified Buckingham potential was employed which consists of a repulsive exponential and an attractive dispersion part represented by $-C / r^{6}$. The erfc term corresponds to the real component of the Ewald sum modelling screened coulombic interactions.

$V_{i j}\left(r_{i j}\right)=A_{i j} \exp \left(-\frac{r_{i j}}{\rho_{i j}}\right)+\frac{q_{i} q_{j}}{4 \pi \varepsilon_{0} r_{i j}} \operatorname{erfc}\left(\frac{r_{i j}}{\beta_{i j}}\right)-\frac{C_{i j}}{r_{i j}^{6}}$

where $A_{i j}$ is the short range repulsion term, $\beta_{i j}$ and $\rho_{i j}$ are adjustable parameters used to reproduce correct bond lengths, $r_{i j}$ is the distance between atoms $i$ and $j$, and $q_{i}$ is the ionic charge of atom $i$ [24]. In the case of silicon and oxygen interactions a 3-body potential was also used to insure better angle distribution functions and better statistic for defects (tetrahedral silica rings statistics) [29].

In order to simulate the growth of silver nanoparticles a Lennard-Jones potential between $\mathrm{Ag}$ atoms is introduced [24]. The same Lennard-Jones potential with a corrective coefficient was also used for the $\mathrm{Ag}$-Eu interaction as follows

$V_{i j}\left(r_{i j}\right)=4 A_{i j}\left[\left(\frac{\rho_{i j}}{r_{i j}}\right)^{12}-\left(\frac{k_{i j} \rho_{i j}}{r_{i j}}\right)^{6}\right]$

The corrective coefficient $k_{i j}$ means that the $\mathrm{Eu}^{3+}$ is attracted by the silver nanoparticles, because the strong cation induces a negative charge on it. $k_{i j}$ is set to 1 for $\mathrm{Ag}-\mathrm{Ag}$ interactions. 
Table 1

Composition of the simulated samples.

\begin{tabular}{llllll}
\hline Atoms & $\mathrm{Eu}$ & $\mathrm{Ag}$ & $\mathrm{Na}$ & $\mathrm{Si}$ & $\mathrm{O}$ \\
\hline Eu-glass & 656 & - & 32112 & 32440 & 81920 \\
Eu-Ag-glass & 656 & 3280 & 28832 & 32440 & 81920
\end{tabular}

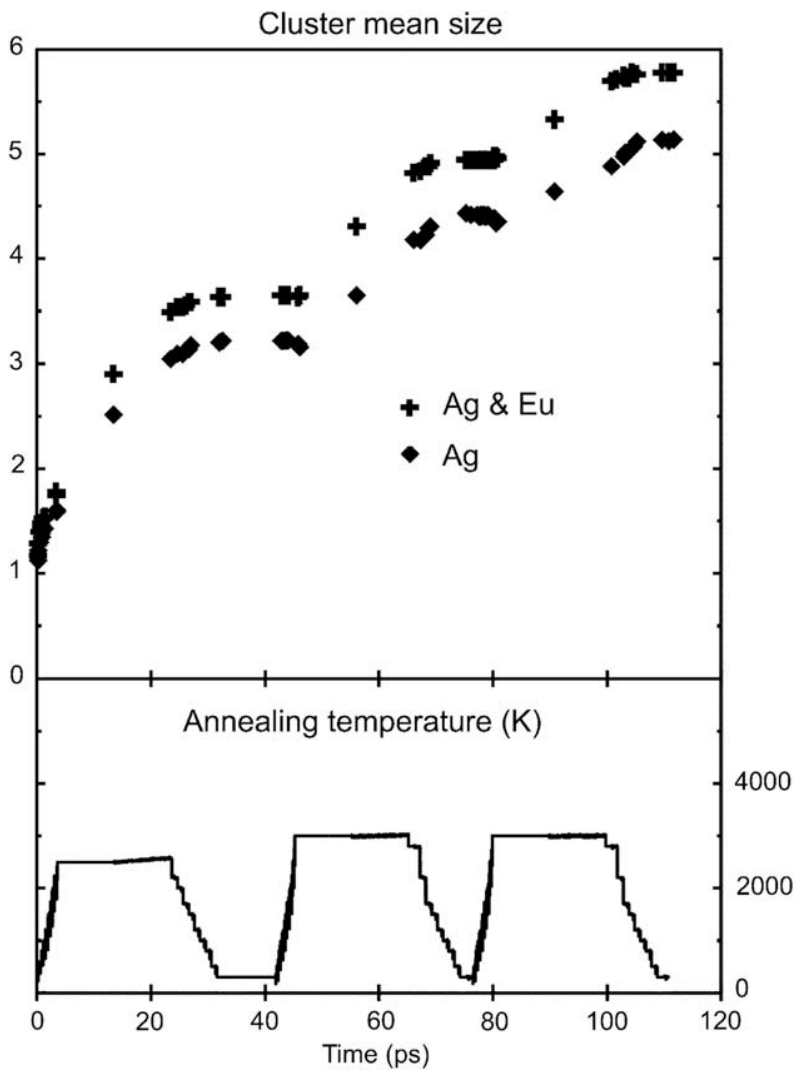

Fig. 1. Temperature (bottom) and mean particle size (top) as a function of the annealing time.

Firstly, the europium doped-glass is prepared by simulating a sample of 147128 atoms. The percentage of europium is 0.45 at.\%.
This percentage is kept in the final composition of the glass containing silver. The sample containing silver is obtained by substitution of $\mathrm{Na}^{+}$by $\mathrm{Ag}^{0}$, simulating both an ionic exchange and the silver reduction. The percentage of silver is 2.23 at.\% (Table 1 ). This simulates a glassy density of $2.616 \mathrm{~g} / \mathrm{cm}^{3}$ within a box of $14.5 \times 14.5 \times 10.1 \mathrm{~nm}^{3}$.

Several stages have been performed in order to get glass samples with silver and europium nanoclusters. Firstly, the europium doped sodosilicate glass is obtained by cooling from the melt. Secondly, sodium ions are substituted by silver. Thirdly, three successive numerical annealings are performed at temperatures that are roughly half the melting temperature of the glass (Fig. 1). It should be notice that the simulated temperatures (several thousand of degrees during $30 \mathrm{ps}$ ) are not realistic but correspond to values often encountered in MD simulations of glasses [30].

\section{Results and discussion}

In a sodosilicate glass, the mixing of sodium and silicon oxide is good. Sodium is a network modifier, breaking numerous $\mathrm{Si}-\mathrm{O}$ bonds and thus allowing a lower melting temperature for the sodosilicate glass than for silica. The substitution of randomly chosen sodium ions by silver ions insures a good homogeneity for the process. This can be seen on the first snapshot (Fig. 2a). One can see a homogeneous repartition of silver atoms and no cluster. In this initial configuration, less than $16 \%$ of the $\mathrm{Ag}$ atoms belong to a cluster of size three or more. Table 2 shows the cluster size distribution per number of $\mathrm{Ag}$ atoms as a function of the $\mathrm{Ag}$ atoms before annealing. The size distribution before annealing shows that essentially one-atom-particles is grown, which confirms the observation in Fig. 2a.

The annealing process reduces the viscosity of the glass, the silver atoms can now migrate and the mean size of clusters increases with the annealing time. In Fig. 1b one can see the snapshot after an annealing of $100 \mathrm{ps}$ and the mean particle size is plotted with respect to the annealing time (Fig. 1). One can then depict that

Table 2

Cluster size distribution before annealing.

\begin{tabular}{lllllll}
\hline Size (atom per cluster) & 1 & 2 & 3 & 4 & 5 & 6 \\
\hline Size $\times$ number/total number $(\%)$ & 64.0 & 20.7 & 8.8 & 3.7 & 1.5 & 1.2 \\
\hline
\end{tabular}
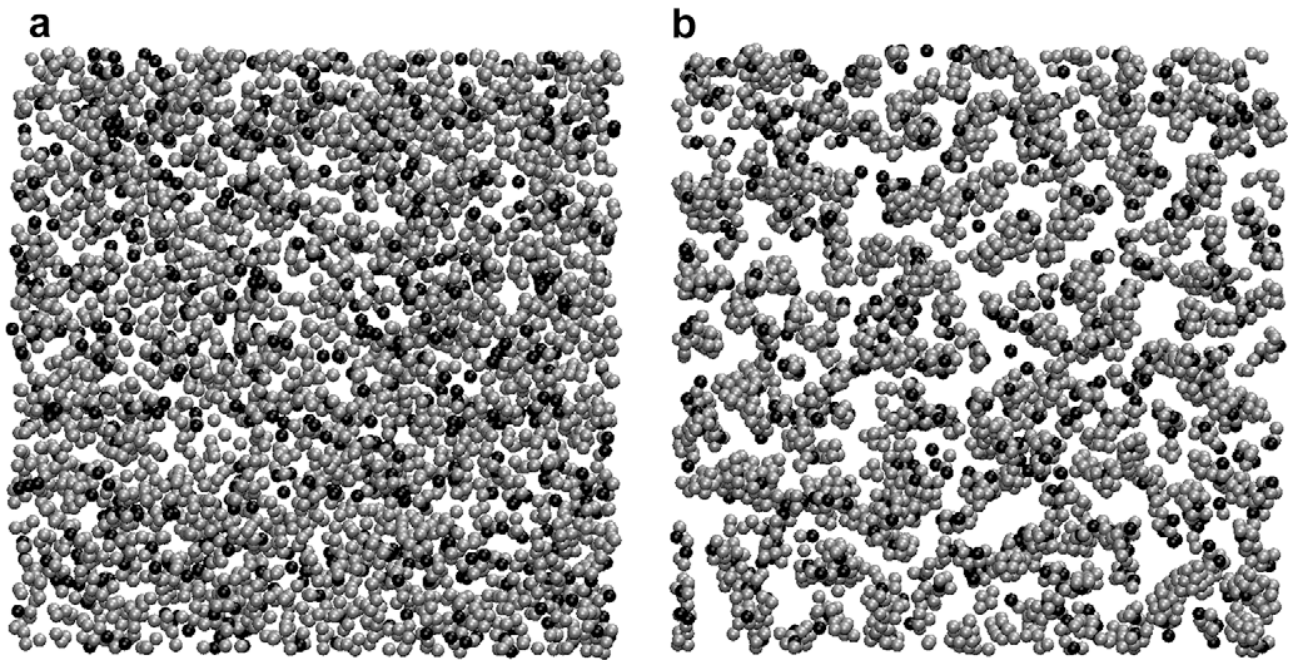

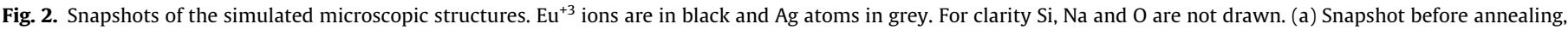
showing a homogeneous repartition of silver atoms and no cluster; and (b) after the annealing procedure pure Ag particles and Ag-Eu nanoalloys have been simulated. 

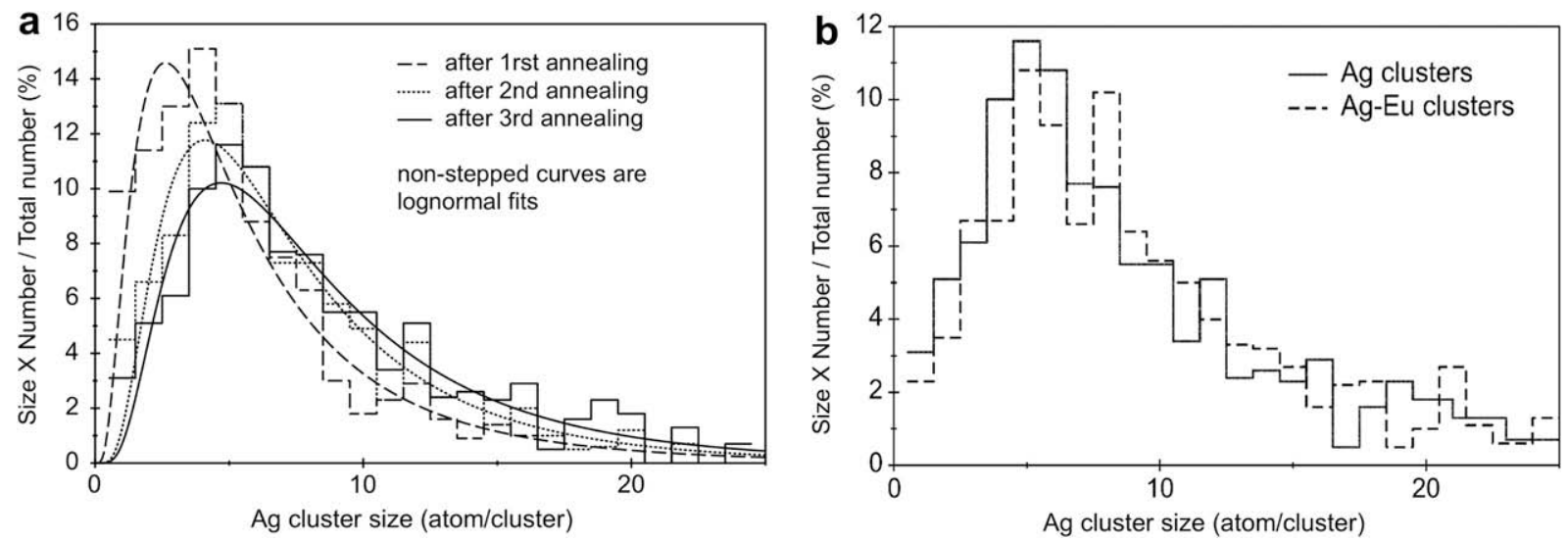

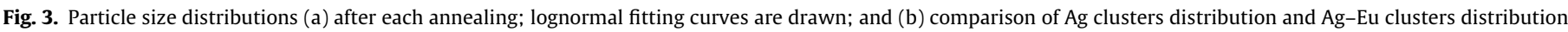
after the 3rd annealing.

before the heat treatment only very few clusters of 2 or 3 atoms have grown can be observed. After the annealing procedure (Fig. 2b) pure Ag as well as Ag-Eu nanoalloys are formed, with different sizes. This nanoalloy composition is explained because the silver nanoparticles are neutral and should attract the strong metal cation $\mathrm{Eu}^{3+}$ by induction. As one can note in Fig. 1, the mean particle contains 5.8 atoms, being 5.2 for $\mathrm{Ag}$ and 0.6 for $\mathrm{Eu}$ in average $\left(\mathrm{Ag}_{5.2} \mathrm{Eu}_{0.6}\right)$, which reproduces satisfactorily the experimental $\mathrm{Ag}_{5}$ Eu composition after EDAX measurements [11]. These latter measurements have been performed in a fluoroborate $\left(\mathrm{B}_{2} \mathrm{O}_{3}+\mathrm{CaF}_{2}\right)$ glass and using the $\mathrm{Sb}_{2} \mathrm{O}_{3}$ for silver reduction proposes.

After annealing processes lognormal curves should fit the particle size distributions (Fig. 3a). The point to be considered is in Fig. 3b. If only Ag particles are considered, lognormal curves always fit the particle size distributions. However, as Ag-Eu nanoparticles are present, lognormal curves does not fit the particle size distribution anymore. Then, at least two systems or a very inhomogeneous system of nanoparticles should grow. This has been observed before in a fluoroborate glass without $\mathrm{Sb}_{2} \mathrm{O}_{3}$ [13].

From the photonic point of view, the $\mathrm{Ag}$-Eu proximity should be observed, because the spectroscopic behaviour of $\mathrm{Ln}^{3+}$ containing glasses is clearly modified. Local electric field enhancement or Ag $\leftrightarrow$ Eu energy transfer are the phenomena invoked to explain the spectroscopic changes $[12,14,15]$.

\section{Concluding remarks}

Based on the fact that the growth and optical properties of silver particles in glass are not completely understood, molecular dynamics simulation has been employed to simulate the growth of $\mathrm{Ag}$ nanoparticles in a sodosilicate glass containing $\mathrm{Eu}^{3+}$ ions. The known potentials for all kind of interactions in glasses and for growing silver particles have been used, and a modified Lennard-Jones potential was successfully introduced to create attraction between the silver particles and the $\mathrm{Eu}^{3+}$. The simulated nanoalloy mean composition $\mathrm{Ag}_{5.2} \mathrm{Eu}_{1.3}$ is satisfactorily close to the experimental average composition $\mathrm{Ag}_{5} \mathrm{Eu}$, obtained after EDAX measurements. Further, the size distributions after heat treatment have been fitted by lognormal curves.

\section{Acknowledgements}

The authors would like to acknowledge RENAMI, CNPq and CAPES (Brazilian agencies) and Université d'Angers for financial support.

\section{References}

[1] L.M. Liz-Marzán, Mater. Today 7 (2004) 26 (February).

[2] C. Wang, Y. Fu, Z. Zhou, Y. Cheng, Z. Xu, Appl. Phys. Lett. 90 (2007) 181119.

[3] O.M. Bakr et al., Angew. Chem. 121 (2009) 6035.

[4] U. Kreibig, M. Vollmer, Optical Properties of Metal Clusters, Springer-Verlag, Berlin, 1996.

[5] W. Ekardt, Metal Clusters, John Wiley and Sons, 1999.

[6] X.C. Yang, M. Dubiel, S. Brunsch, H. Hofmeister, J. Non-Cryst. Solids 328 (2003) 123.

[7] H. Hofmeister, M. Dubiel, G.L. Tan, K.-D. Schicke, Phys. Status Solidi (a) 202 (2005) 2321

[8] J.A. Jimenez, S. Lysenko, G. Zhang, H. Liu, J. Mater. Sci 42 (2007) 1856.

[9] M. Dubiel, R. Schneider, H. Hofmeister, K.-D. Schicke, J.C. Pivin, Eur. Phys. J. D 43 (2007) 291.

[10] O.L. Malta, P.A. Santa-Cruz, G.F. de Sá, F. Auzel, J. Lumin. 33 (1985) 261.

[11] G.F. de Sá, W.M. Azevedo, O.L. Malta, H. Dexpert, J. Less-Common Met. 148 (1989) 387.

[12] O.L. Malta, M.A. Couto dos Santos, Chem. Phys. Lett. 174 (1990) 13

[13] M.A. Couto dos Santos, O.L. Malta, G.F. de Sá, J. Alloys Compd. 180 (1992) 215

[14] E.L. Falcão-Filho, C.B. de Araújo, A. Galembeck, M.M. Oliveira, A.J.G. Zarbin, J. Opt. Soc. Am. B 22 (2005) 2444

[15] L.P. Naranjo, O.L. Malta, P.A. Santa-Cruz, C.B. de Araújo, L.R.P. Kassab, Appl. Phys. Lett. 87 (2005) 241914.

[16] M. Mattarelli et al., J. Non-Cryst. Solids 353 (2007) 498.

[17] J.R. Morones, J.L. Elechiguerra, A. Camacho, K. Holt, J.B. Kouri, J.T. Ramirez, M.J. Yacaman, Nanotechnology 16 (2005) 2346.

[18] S. Ghosh, A.K. Banthia, J. Mater. Sci. 42 (2007) 118.

[19] J. Zhang, Y. Fu, H. Mustafa, J.R. Lakowicz, J. Phys. Chem. C 112 (2008) 18.

[20] W.Y. Awliya, A.M. El-Sahn, Oper. Dent. 33 (2008) 31.

[21] J.H. Lin, C.Y. He, Y. Zhao, S.S. Zhang, Sens. Actuators B: Chem. 137 (2009) 768.

[22] S.J. Ahn, S.J. Lee, J.K. Kook, B.S. Lim, Dent. Mater. 25 (2009) 206.

[23] J. Du, A.N. Cormack, J. Non-Cryst. Solids 351 (2005) 2263.

[24] D. Timpel, K. Scheerschmidt, S.H. Garofalini, J. Non-Cryst. Solids 221 (1997) 187.

[25] H. Iyetomi, P. Vashshita, R.K. Kalia, J. Non-Cryst. Solids 262 (2000) 135

[26] A. Monteil et al., J. Non-Cryst. Solids 348 (2004) 44.

[27] M.A.P. Silva, J.P. Rino, A. Monteil, S.J.L. Ribeiro, Y. Messaddeq, J. Chem. Phys. 121 (2004) 7413.

[28] G. Dantelle, M. Mortier, A. Monteil, S. Chaussedent, M.A.P. Silva, J. Chem. Phys. 127 (2007) 094509.

[29] B.P. Feuston, S.H. Garofalini, J. Chem. Phys. 89 (1988) 5818.

[30] K. Vollmayr, W. Kob, K. Binder, Phys. Rev. B 54 (1996) 15808. 